\title{
Combination of Psychiatric and Psychological Approaches in the Assessment and Treatment of Sexual Offenders
}

\author{
O Chan, S Lam
}

\begin{abstract}
This review discusses the association between mental disorders and sexual offending, and provides an overview of the combination of psychiatric and psychological approaches to assess and treat sexual offenders at the Sex Offender Evaluation and Treatment Unit in Siu Lam Psychiatric Centre in Hong Kong.
\end{abstract}

Key words: Hospitals, psychiatric; Mental disorders; Paraphilic disorders; Psychology, clinical; Sex offenses

Dr Oliver Chan, MBChB (CUHK), MRCPsych, FHKCPsych, FHKAM (Psychiatry), Department of Forensic Psychiatry, Castle Peak Hospital, Hong Kong

Ms Sarina Lam, MPhil (Clinical Psychologist), Registered Clinical Psychologist (HKPS), Correctional Services Department, Hong Kong

Address for correspondence: $\mathrm{Dr}$ Oliver Chan, Department of Forensic Psychiatry, Castle Peak Hospital, 15 Tsing Chung Koon Road, Castle Peak Hospital, New Territories, Hong Kong.

Tel:(852)24567111; Fax: (852)24631644; Email: co258@ha.org.hk

Submitted: 29 March 2018; Accepted: 31 July 2018

\section{Introduction}

Traditionally, assessment and treatment of sexual offenders in prison is mostly performed by psychologists. Increasing evidence suggested that a psychiatric perspective contributes to better understanding of sexual offending, and thus improvement in the training of psychiatrists has been called for. ${ }^{1}$ This review discusses the association between mental disorders and sexual offending, and provides an overview of the combination of psychiatric and psychological approaches to assess and treat sexual offenders in Hong Kong.

\section{Psychiatric disorders and sexual offending}

An epidemiological study reported an increased rate of sexual offending among psychiatric patients. ${ }^{2}$ Sexual offenders have a greater prevalence of axis I mental disorders, in particular mood disorders, anxiety disorders, autistic spectrum disorders, paraphilic disorders, and attention deficit hyperactivity disorder., ${ }^{3,4}$ Kluver Bucy Syndrome, traumatic brain injury, and adverse effects of certain medications (eg, dopaminergic agonists in the treatment of Parkinson's disease) may result in hypersexuality and offending behaviour. Thus, for sexual offenders who have treatable psychiatric disorders, psychiatrists have a role in the assessment and treatment of sexual offending behaviours.

\section{Paraphilia}

Paraphilia is defined as any intense and persistent sexual interest other than sexual interest in genital stimulation or preparatory fondling with phenotypically mature, consenting human partners. Many patients with paraphilic disorder are only first diagnosed after they have committed a criminal offence. Forensic psychiatrists are pivotal in identifying such a disorder and other co-morbid mental illnesses. Paraphilia is not regarded as a mental disorder and is not necessarily associated with criminal offence. Treatment goals for paraphilia are to control paraphiliac fantasies, behaviour, and sexual urges, and to decrease the level of distress of the paraphiliac subject. A combination of psychiatric and psychological treatment may best reduce the risk of recidivism. ${ }^{5}$

The World Federation of Societies of Biological Psychiatry has published guidelines for pharmacological intervention for people with paraphilic disorder. ${ }^{5}$ Nonetheless, robust controlled studies are still lacking given the methodological and ethical limitations. ${ }^{6}$ Three types of pharmacological agents are commonly used: selective serotonin reuptake inhibitors, synthetic steroidal analogues, and gonadotropin-releasing hormone analogues.

Selective serotonin reuptake inhibitors are useful to treat paraphilic disorders, owing to the role of serotonin and specific subtypes of 5HT brain receptors on sexual behaviour. ${ }^{7}$ Serotonin is the main neurotransmitter associated with impulsivity in the sense of behaviour inhibition. Continuous administration of the drug increases the level of brain-derived neurotrophic factor, and results in increased neuronal plasticity and increased capacity for changing behaviour. ${ }^{8}$ Selective serotonin reuptake inhibitors are effective in treating paraphilia associated with axis I comorbidities, including obsessive-compulsive disorders, 
depressive disorders, and impulse-control disorders. They are generally well tolerated even on a long-term basis.

Anti-androgen treatment may be indicated for paraphilic disorders characterised by intense and frequent deviant desire and arousal, which predispose an individual to severe paraphiliac behaviour (eg, serial rape or paedophilic behaviour). Frequency of sexual behaviour is measured by the number of total sexual outlets. ${ }^{9}$ Anti-androgen has been used to reduce deviant sexual thoughts or fantasies and to aid engagement in psychological programmes. ${ }^{10}$ It serves to lower testosterone and hence sexual drive, aggression, violent behaviour, and recidivism in sexual offending. ${ }^{11,12}$ There is a threshold level of testosterone below which sexual arousal is substantially reduced. ${ }^{12}$ Anti-androgen can be used in sexual offenders with mental retardation or cognitive dysfunctions associated with neuropsychiatric conditions. Informed consent (with the involvement of carers in mentally incapacitated patients) is necessary. Among anti-androgen drugs, cyproterone acetate and medroxyprogesterone acetate can be given orally or as intramuscular depot injections. Luteinising hormone releasing hormone agonists are used for treatment of severe sexual deviations in some European countries. Cognitive behavioural therapy together with luteinising hormone releasing hormone agonist leuprolide acetate significantly decreased paedophilic urge and masturbatory frequency, compared with cognitive behavioural therapy alone. ${ }^{13}$ The clinical effect waned after 12 months of saline placebo treatment. Nonetheless, anti-androgen treatment has risks of thromboembolism, hypertension, osteoporosis, liver dysfunction, and feminisation. ${ }^{14}$ Careful review of the medical history before treatment, regular monitoring for any adverse effects, and prescription of calcium carbonate and vitamin D to prevent bone mineral loss are necessary. The effects are generally reversible within 1-2 months with regeneration of testicular Leydig cells. ${ }^{15}$

\section{Psychiatric services in Hong Kong}

In Hong Kong, the Department of Forensic Psychiatry of the Castle Peak Hospital is the only provider of forensic psychiatric services in a prison setting. It collaborates with clinical psychologists of the Correctional Services Department to provide assessment and treatment to sexual offenders with mental health needs. Clinical care can be extended even after the offender is released from custody. In 2012, the Tuen Mun Mental Health Centre was established to provide specialist out-patient services to patients with complex mental health and psychosexual needs, with an aim to reduce recidivism and victimisation. The centre has an annual attendance of $>150$; most patients have a diagnosis of a paraphilic disorder with a co-morbid axis I disorder, including social anxiety disorder, depression, impulse control disorder, or psychotic disorder. Personality disorder is also common, including schizoid personality disorder or dissocial personality disorder. A combination of pharmacological treatments (namely selective serotonin reuptake inhibitor and/or anti-androgen) and clinical psychological treatment are provided.

\section{Psychological approach}

Psychological factors crucial to sexual reoffending include loneliness, ${ }^{16-18}$ sexual preoccupation, ${ }^{19}$ and using sex as a coping mechanism. ${ }^{20}$ Typically, these offenders do not have any stable, secure intimate adult relationship. Many have restricted range of interests or lack meaningful engagements. They end up indulging themselves in impersonal sex such as prostitutions, pornography, promiscuity, and masturbating with deviant sexual fantasy as means to cope with boredom, emptiness, and distress. Failure to address the above can lead to sexual reoffending. However, sexual offenders are defensive and less motivated to seek treatment owing to social stigma.

\section{Psychological treatment}

In 1998, the Sex Offender Evaluation and Treatment Unit (ETU) was set up in Siu Lam Psychiatric Centre to help persons in custody who have committed sexual offences to lead a law-abiding and constructive life after release.

The ETU adheres to the Risk-Need-Responsivity Model, ${ }^{21}$ which is effective in assessment and treatment of offenders. It stipulates that treatment length and intensity should be contingent on reoffending risk (the risk principle). Treatment should be targeted on problems that are conducive to reoffending, or otherwise known as criminogenic needs or dynamic risk factors (the need principle). Treatment should be delivered in a way to maximise offenders' ability to learn, taking into consideration the offenders' ability, learning style and motivation (the responsivity principle).

Persons in custody convicted of sexual offences are transferred to ETU for risk assessment, using STATIC 99R, ${ }^{22,23}$ STABLE 2007, ${ }^{24,25}$, Hong Kong Risk Assessment Scales for Sex Offenders - Revised, ${ }^{26}$ and Hong Kong Needs Assessment Scales for Sex Offenders. ${ }^{27}$ Salient risk predictors include age, offence history, presence of paraphilic disorder, lacking intimate relationship, mood dysregulation, sexual preoccupation, and sex as a coping mechanism. Risk predictors associated with loneliness and inability to build intimate relationships are strongly correlated with sexual reoffending. In Hong Kong, additional predictors of recidivism include using the Internet to acquaint with potential victims or downloading child pornography and the lack of tangible support after release from prison.

Persons in custody first undergo a 2-to-4-week sexual offender orientation programme at ETU. Those with low reoffending risk are discharged to other institutions. Those with moderate to high risk are assigned to moderateintensity (6-8 months) and high-intensity (12-14 months) programmes at ETU, respectively.

Programmes involve mainly group therapy (that targets on criminogenic needs) supplemented with individual treatment and skills training. The treatment 
content mirrors those changeable risk factors (Table 1). Those with psychiatric disorders, including paraphilic disorders, are referred to psychiatrists for consideration of pharmacological treatment.

Traditionally, cognitive-behavioural therapy was the backbone treatment for sexual offenders. ${ }^{28}$ It aimed to identify and rectify distorted cognitions conducive to offending behaviours, mood problems, and interpersonal difficulties. Relapse prevention model (originated from the treatment of addiction ${ }^{29}$ ) was also applied to help sexual offenders to recognise and cope with high-risk situations for reoffending. ${ }^{30}$ Current treatment has shifted to a strengthbased approach, namely the Good Lives Model ${ }^{31}$ to promote a good life by enhancing strengths, skills, and abilities rather than suppressing negative behaviour. Enhancing sexual offenders' overall functioning leads them to attain the goals of a good life, which in turn reduces their need to offend. At ETU, persons in custody are encouraged to identify their life dreams and goals. Efforts are made to explore and amplify their hidden strengths such that they have greater ability and confidence to effect personal change.

By centralising sexual offenders with treatment needs in a therapeutic community at ETU, stigma associated with sexual offending is attenuated. At ETU, persons in custody feel more secure and are more likely to confess and receive treatment. Therapeutic community provides more opportunities to increase the intensity of the treatment experience beyond group therapy sessions and is regarded as an extension of the group therapy process. ${ }^{32}$ Persons in custody are encouraged to practise their newly acquired personal and interpersonal skills in their daily life; this helps generalisation and maintenance of the treatment gain.

For quality assurance, ETU is subjected to regular service review by an advisory panel comprising local and overseas experts. Dr William Marshall from Rockwood Psychological Services of Canada is the founding advisor. Mr Robert McGrath, previous Clinical Director of the Vermont Treatment Program for Sexual Aggressors at the Vermont Department of Corrections, USA, and Professor Fanny MC Cheung, a psychologist from the Chinese
University of Hong Kong are current panel members. Programme contents are periodically refined based on updated research and the international best practice. Latest service review in 2013 considered ETU as one of the best of its kind in Asia.

\section{Profile of sexual offenders}

In 2017, 227 persons were admitted to the correctional services owing to sexual offences. Of them, 115 (mean \pm standard deviation age, $39.5 \pm 13.4$ years) who were mentally stable and had at least 3 weeks of remaining sentence were admitted to various programmes at ETU. Approximately $80 \%$ of them were willing to stay for treatment after the orientation programme. For those who refused treatment, most denied their offence or were in the process of appeal. Of those who accepted treatment, $64.4 \%$ were of at least low-to-moderate risk of sexual reoffending and needed intensive treatment. Typical offences included child molestation, more intrusive forms of indecent assault, and rape; $<1 \%$ involved sexual murder. Of the victims, $90.4 \%$ were female and $33.9 \%$ were children aged $<16$ years. The victims were mostly strangers (50.4\%) and acquaintances $(42.6 \%)$; only $6.1 \%$ were family members. Sexual offences associated with acquaintances usually involved teacher-students relationship (teachers included scout leader, private tutor, music teacher, sports coach) and friends acquired via internet. Base on the STABLE 2007, the most common criminogenic needs identified were lack of stable intimate relationship (70\%), sexual preoccupation (61\%), and poor problem-solving skills (54\%). The most common paraphilic disorders were frotteuristic disorder $(12 / 74=16.2 \%)$, voyeuristic disorder $(7 / 53=13.2 \%)$, and paedophilic disorder $(9 / 74=12.2 \%)$.

\section{Outcome evaluation}

Recidivism as outcome measure is not feasible owing to the lack of high-risk untreated sexual offenders as controls. A battery of psychological tests is used to assess treatment

Table 1. Treatment modules of programmes in the Sex Offender Evaluation and Treatment Unit.

\begin{tabular}{|ll|}
\hline Treatment modules & Details \\
\hline Autobiography & Identification of one's life goal and strength \\
\hline Understanding offending behaviour & Causation of offence and high-risk situations \\
\hline Self esteem & Enhancement of self-efficacy for change \\
\hline Cognitive restructuring & $\begin{array}{l}\text { Rectification of distorted schemas related to offence, emotions and } \\
\text { interpersonal relationship }\end{array}$ \\
\hline Mood management & Coping with negative mood by adaptive means other than sex \\
\hline Relationship skills & Address risk factor of loneliness \\
\hline Healthy sexuality & Tackle sexual preoccupation and establish healthy sexual life \\
\hline Self-management plan & Integration of above to actualise a fulfilling life \\
\hline
\end{tabular}


Table 2.Pre- and post-treatment scores of selected at-risk sexual offenders at the Sex Offender Evaluation and Treatment Unit during 2002-2017.

\begin{tabular}{|c|c|c|c|c|c|}
\hline Outcome measure & $\begin{array}{c}\text { No. of } \\
\text { participants }\end{array}$ & $\begin{array}{l}\text { Pre- } \\
\text { treatment } \\
\text { score }\end{array}$ & $\begin{array}{l}\text { Post- } \\
\text { treatment } \\
\text { score }\end{array}$ & $t$ Value & p Value \\
\hline \multicolumn{6}{|l|}{ Rectification of criminal thinking } \\
\hline Abel and Becker Cognition Scale ${ }^{33}$ & 250 & 115.95 & 128.36 & -11.52 & $<0.001$ \\
\hline Burt Rape Myths Scale ${ }^{34}$ & 250 & 58.65 & 48.62 & 13.14 & $<0.001$ \\
\hline Attitudes Towards Rape Victims Scale 35 & 246 & 33.46 & 23.69 & 11.63 & $<0.001$ \\
\hline \multicolumn{6}{|l|}{ Relapse prevention } \\
\hline Relapse Prevention Questionnaires ${ }^{36}$ & 190 & 15.43 & 21.23 & -12.04 & $<0.001$ \\
\hline \multicolumn{6}{|l|}{ Loneliness } \\
\hline UCLA Loneliness Scale $^{37}$ & 80 (since 2011) & 50.09 & 41.41 & 7.78 & $<0.001$ \\
\hline \multicolumn{6}{|l|}{ Self-esteem } \\
\hline Rosenberg Self-Esteem Scale ${ }^{38}$ & 68 (since 2011 ) & 25.54 & 31.13 & -10.57 & $<0.001$ \\
\hline
\end{tabular}

effectiveness. Rectification of criminal thinking is measured using the Abel and Becker Cognition Scale, ${ }^{33}$ the Burt Rape Myths Scale, ${ }^{34}$ and the Attitudes Towards Rape Victims Scale. ${ }^{35}$ Relapse prevention is measured using the Relapse Prevention Questionnaires. ${ }^{36}$ Loneliness is measured using the UCLA Loneliness Scale. ${ }^{37}$ Self-esteem is measured using the Rosenberg Self-Esteem Scale. ${ }^{38}$ Pre- and posttreatment scores of selected at-risk sexual offenders during 2002-2017 were compared using paired t test. Results suggested that treatment programmes at ETU effectively rectified criminal thinking and improved relapse prevention skills, loneliness, and self-esteem (Table 2).

\section{Conclusion}

Collaboration between psychiatrists and psychologists in assessment and treatment of sexual offenders with mental health and psychological needs can decrease recidivism of sexual-offending behaviour.

\section{Acknowledgements}

We thank Dr Cola Lo, clinical psychologist of Castle Peak Hospital, for her professionalism in providing psychological intervention to the attendants of the specialist out-patient clinic in the Tuen Mun Mental Health Centre since 2012.

\section{Declaration}

All authors have no conflicts of interest to disclose.

\section{References}

1. Gordon H, Grubin D. Psychiatric aspects of the assessment and treatment of sex offenders. Adv Psychiatr Treat 2004;10:73-
80. Crossref

2. Fazel S, Sjostedt G, Langstrom N, Grann M. Severe mental illness and risk of sexual offending in men: a case-control study based on Swedish national registers. J Clin Psychiatry 2007;68:588-96. Crossref

3. Kafka M. Axis I psychiatric disorders, paraphilic sexual offending and implications for pharmacological treatment. Isr J Psychiatry Relat Sci 2012;49:255-61.

4. Kafka MP, Hennen J. A DSM-IV Axis I comorbidity study of males $(\mathrm{n}=120)$ with paraphiliac and paraphilia-related disorders. Sex Abuse 2002;14:349-66. Crossref

5. Thibaut F, De La Barra F, Gordon H, Cosyns P, Bradford JM; WFSBP Task Force on Sexual Disorders. The World Federation of Societies of Biological Psychiatry (WFSBP) guidelines for the biological treatment of paraphilias. World J Biol Psychiatry 2010;11:604-55. Crossref

6. Briken P, Kafka MP. Pharmacological treatments for paraphilic patients and sexual offenders. Curr Opin Psychiatry 2007;20:609-13. Crossref

7. Bradford JM. The neurobiology, neuropharmacology, and pharmacological treatment of the paraphilias and compulsive sexual behaviour. Can J Psychiatry 2001;46:26-34. Crossref

8. Beech AR, Mitchell IJ. A neurobiological perspective on attachment problems in sexual offenders and the role of selective serotonin reuptake inhibitors in the treatment of such problems. Clin Psychol Rev 2005;25:153-82. Crossref

9. Kinsey AC, Pomeroy WM, Martin CE. Sexual Behaviour in the Human Male. Philadelphia: WB Saunders; 1948.

10. Saleh FM, Grudzinskas AJ Jr, Malin HM, Dwyer RG. The management of sex offenders: perspectives for psychiatry. Harv Rev Psychiatry 2010;18:359-68. Crossref

11. Studer LH, Aylwin AS, Reddon JR. Testosterone, sexual offense recidivism, and treatment effect among adult male sex offenders. Sex Abuse 2005;17:171-81. Crossref

12. Bradford JM, Pawlak A. Double-blind placebo crossover study of cyproterone acetate in the treatment of the paraphilias. Arch Sex Behav 1993;22:383-402. Crossref

13. Schober JM, Kuhn PJ, Kovacs PG, Earle JH, Byrne PM, Fries RA. Leuprolide acetate suppresses pedophilic urges and arousability. Arch Sex Behav 2005;34:691-705. Crossref

14. Brotherton J. Effect of oral cyproterone acetate on urinary and serum FSH and LH levels in adult males being treated for hypersexuality. J Reprod Fertil 1974;36:177-87. Crossref

15. Garcia FD, Thibaut F. Current concepts in the pharmacotherapy of 
paraphilias. Drugs 2011;71:771-90. Crossref

16. Marshall WL, Marshall LE, Serran GA, Fernandez YM. Treating Sexual Offenders: an Integrated Approach. New York: Routledge; 2006.

17. Ward T, Polaschek DLL, Beech AR. Theories of Sexual Offending. Chichester: John Wiley \& Sons; 2006.

18. Andrews DA, Bonta J, Hoge RD. Classification for effective rehabilitation: rediscovering psychology. Crim Justice Behav 1990;17:19-52. Crossref

19. Langstrom N, Hanson RK. High rates of sexual behavior in the general population: correlates and predictors. Arch Sex Behav 2006;35:3752. Crossref

20. Cortoni F, Marshall WL. Sex as a coping strategy and its relationship to juvenile sexual history and intimacy in sexual offenders. Sex Abuse 2001;13:27-43. Crossref

21. Skeem JL, Steadman HJ, Manchak SM. Applicability of the RiskNeed-Responsivity Model to persons with mental illness involved in the criminal justice system. Psychiatr Serv 2015;66:916-22. Crossref

22. Hanson RK, Thornton D. Improving risk assessments for sexual offenders: a comparison of three actuarial scales. Law Hum Behav 2000;24:119-36. Crossref

23. Helmus L, Hanson RK, Morton-Bourgon KE. International comparisons of the validity of actuarial risk tools for sexual offenders, with a focus on Static-99. In: Boer DP, Craig LA, Eher R, Miner $\mathrm{MH}$, Pfafflin F, editors. International Perspectives on the Assessment and Treatment of Sexual Offenders: Theory, Practice, and Research. Chichester: Wiley-Blackwell; 2011: 57-83. Crossref

24. Hanson RK, Harris AJ, Scott TL, Helmus L. Assessing the risk of sexual offenders on community supervision: The Dynamic Supervision Project. User Report, Corrections Research, Ottawa: Public Safety Canada; 2007.

25. Harris AJ, Hanson RK. Clinical, actuarial and dynamic risk assessment of sexual offenders: why do things keep changing? J Sex Aggress 2010;16:296-310. Crossref

26. Final study report on risks assessment tools for adult sex offenders (CSO 42/2009). Department of Psychology, The Chinese University of Hong Kong, Hong Kong. 2015.

27. Final study report on needs assessment tools for adult sex offenders (CSO 92/2009). Department of Psychology, The Chinese University of Hong Kong, Hong Kong. 2015.

28. Hanson RK, Gordon A, Harris AJ, Marques JK, Murphy W, Quinsey $\mathrm{VL}$, et al. First report of the collaborative outcome data project on the effectiveness of psychological treatment for sexual offenders. Sex Abuse 2002;14:169-97. Crossref

29. Marlatt GA. Situational determinants of relapse and skill-training interventions. In: Marlatt GA, Gordon JR, editors. Relapse Prevention: Maintenance Strategies in the Treatment of Addictive Behaviors. New York: Guilford Press; 1985:71-127.

30. Laws DR, Hudson SM, Ward T. Remaking Relapse Prevention with Sexual Offenders: a Sourcebook. Thousand Oaks, CA: Sage Publications; 2000.

31. Ward T, Stewart CA. The treatment of sex offenders: risk management and good lives. Prof Psychol Res Pr 2003;34:353. Crossref

32. Ware J, Frost A, Hoy A. A review of the use of therapeutic communities with sexual offenders. Int J Offender Ther Comp Criminol 2010;54:72142. Crossref

33. Abel GG, Becker JV, Cunningham-Rathner J. Complications, consent, and cognitions in sex between children and adults. Int J Law Psychiatry 1984;7:89-103. Crossref

34. Burt MR. Cultural myths and supports for rape. J Pers Soc Psychol 1980;38:217-30. Crossref

35. Ward C. The Attitudes Toward Rape Victims Scale: construction, validation, and cross-cultural applicability. Psychol Women Q 1988;12:127-46. Crossref

36. Beckett RC, Fisher D, Mann R, Thornton D. The relapse prevention questionnaire and interview. In: Eldridge H. Therapists Guide for Maintaining Change: Relapse Prevention for Adult Male Perpetrators of Child Sexual Abuse. SAGE Publications; 1998:445-73.

37. Russell D, Peplau LA, Ferguson ML. Developing a measure of loneliness. J Pers Assess 1978;42:290-4. Crossref

38. Rosenberg M. Society and the Adolescent Self-image. Princeton, NJ: Princeton University Press; 1965 . Crossref 